\section{(6) OPEN ACCESS}

PAPER

\title{
Contractualist reasoning, HIV cure clinical trials, and the moral (ir)relevance of the risk/benefit ratio
}

\author{
Rahul Kumar
}

\begin{abstract}
Correspondence to
Dr Rahul Kumar, Department of Philosophy, Queen's University, Kingston, Ontario, Canada K7L 3N6: rahul.kumar@queensu.ca
\end{abstract}

Received 18 January 2016 Revised 11 August 2016 Accepted 17 August 2016 Published Online First 2 September 2016

\begin{abstract}
Institutional review boards (IRB) normally require of a morally defensible clinical trial that any trial participant will benefit from the inquiry, or at least not be exposed to a significant risk of having their prospects worsened by participating. Stage 1 HIV cure trials tend not to meet this requirement. Does that show them to be morally indefensible? Utilitarian thinking about this question supports a negative answer. But one might reasonably expect a Kantian moral theory to support the conclusion that exposing trial participants to a significant risk of their prospects being worsened by their participation to be morally indefensible, on grounds that this would be a clear case of using a person as a mere means. In this paper, I argue, drawing on Kantian contractualist thinking, that requiring the risk/benefit ratio for participants be positive if a trial is to be morally defensible does not in fact gain any support from Kantian thinking about morality.
\end{abstract}

\section{INTRODUCTION}

Institutional review boards (IRB) generally hold that proceeding with a clinical trial is only morally defensible if any trial participant will benefit from its inquiry (or at the very least, not run a significant risk of his prospects becoming much worse). That is, clinical equipoise requires that the risk/benefit ratio associated with a trial be favourable.

Some early-phase HIV cure studies that are planned or are underway arguably fall afoul of this requirement. ${ }^{1}$ Participants in such studies are often exposed to a non-trivial risk of harm or death whose magnitude is difficult to estimate. And though they stand to benefit from participating, the benefit is not significant enough to make the risk/ benefit ratio associated with this type of early-phase trial other than very poor. For example, an individual infected with HIV can control the associated symptoms by simply sticking to a regime of taking one antiviral pill a day. If the treatment is started early enough, someone infected with HIV can, as far as we know, be expected to live as long as one not carrying HIV. There are other benefits associated with being cured of HIV, such as that of not having to live with the stigma associated with the disease. ${ }^{2}$ But that alone is not enough to render the risk/benefit ratio associated with early-phase HIV cure trials favourable. If proceeding with a clinical trial is only ethically defensible if the risk/benefit ratio for participants is favourable, proposed phase I HIV cure studies should not be cleared to proceed.
Requiring a favourable risk/benefit ratio as a condition for allowing a clinical trial to proceed is widely accepted as a regulation. But that is not a good reason to take the requirement to be morally justified. What the most plausible justification for it looks like, if it can be morally justified, is a matter of debate. ${ }^{3}$ In this discussion I will look closely at one potentially promising moral justification for the requirement. It holds that requiring the risk/ benefit ratio be favourable is a plausible regulatory expression of the moral idea that clinical trial participants must not be exploited, ${ }^{3}$ a thought that I will take to be an intuitive way of appealing to the Kantian injunction against using a person as a mere means, rather than as an end in himself.

The argument connecting this injunction with requiring a favourable risk/benefit ratio goes as follows: say a person, having been fully informed of both the harms that could befall him if he participates in the trial and the potential value of results, consents to participate. We still don't know whether participating is something he has reason to do. It isn't uncommon, after all, for individuals to knowingly and willingly enter into relationships that are in some way exploitative. Further, the potential value of a trial's results for the general population creates a strong psychological incentive for researchers to overlook the exploitative character of the relationship between them and the trial participants. Requiring a favourable risk/benefit ratio protects trial participants from entering into an exploitative relationship in which they are used as a mere means for the achievement of the greater good.

Whether this is in fact a good argument is difficult to assess; there are a host of difficulties surrounding what does and does not count as using a person as a mere means. ${ }^{4}$ The argument can be restated in a more tractable form, however, if we restate it in the terms of Scanlon's broadly Kantian theory of permissible conduct, contractualism. The contractualist principle-that conduct is only morally permissible if so acting is justifiable to each person on grounds no individual can reasonably reject-is widely taken to be an appealing recent articulation of the Kantian injunction to always relate to others as ends in themselves. ${ }^{45}$ If requiring a favourable risk/benefit ratio is a regulatory expression of the requirement that persons ought always to be treated as ends and not mere means, it is reasonable to look to the resources of the contractualist approach to articulate a plausible theoretical rationale for that requirement.

What I shall argue is that contractualist reasoning cannot be used to vindicate the favourable risk/ 
benefit ratio requirement as morally justified. That is not, of course, grounds for concluding that no Kantian approach to moral reasoning will yield plausible grounds for the risk/benefit ratio requirement. But it is an important part of the case for that conclusion.

The discussion is organised as follows: in the first part of the paper, I shall assess a general argument for why contractualist reasoning cannot be appealed to as a justification for the favourable risk/benefit ratio requirement. It holds that permitting early-phase HIV cure trials to proceed cannot be justified on contractualist grounds because contractualist reasoning rules out doing anything that exposes another or others to a risk of harm. Contractualist reasoning appears, therefore, to rule out the moral permissibility of proceeding with, not just early-phase HIV cure trials, but any clinical trial, regardless of whether the risk/benefit ratio is favourable.

In the second part of the paper, I shall argue that contractualist reasoning does not have this implausible implication. There is therefore no in principle reason for thinking that proceeding with most clinical trials cannot be morally justified on contractualist grounds. But, I will go on to argue, there are good nonconsequentialist reasons that the contractualist approach brings into relief for not requiring a favourable risk/benefit ratio as a condition for morally permitting a trial to proceed. With these on the table, the case for rejecting the favourable risk/benefit ratio requirement, I submit, looks to be more plausible than it might at first blush seem.

\section{A BRIEF OVERVIEW OF THE CONTRACTUALIST APPROACH}

Contractualism says that conduct wrongs another, or is impermissible, if its performance under the circumstances would be disallowed by any principle, for the regulation of the type of conduct in question, that is justifiable to each person on grounds no one could reasonably reject. Whether a principle is justifiable to each person turns solely on comparing its implications for individuals to the implications for individuals of candidate alternative principles, as assessed from the various points of view of whose who stand to be affected by the proposed permission. Considerations of aggregate benefit or burden, or the value of states of affairs, have no role to play in assessing whether a principle is one no one can reasonably reject. If a principle is one no individual can reasonably reject, the strongest objection to it will not be as strong as the objections that can be pressed from other points of view against every plausible alternative. It is the principle whose implications are 'most acceptable to the person to whom it is least acceptable'. ${ }^{6}$

Importantly, contractualism does not employ anything like a 'veil of ignorance' device. That is, a justified principle is one that is justifiable to any person for whom it has implications and who is fully aware of its implications for his life. Consider, for example, the question of whether it is morally justifiable to permit painful and debilitating medical experimentation, the results of which will contribute to developing a cure for a disease that results in unpleasant, but brief, recurring headaches for a large number of people. Individuals are to be chosen by lottery to be involuntarily experimented on. If we ask whether doing so is justifiable to each person who might be chosen, assuming no one knows whether he will in fact be chosen, it looks like the answer is yes. Assuming a very large population, the risk of being chosen is low, and the potential benefit significant enough that, from each person's point of view, the gamble of being chosen as an experimental subject looks to be one worth taking. By contractualist lights, however, defending the permissibility of involuntarily experimenting on individuals requires that the permissibility of doing so be justifiable even to the point of view of one who will be experimented on and knows he is to be experimented on. That is, what is needed is a good case for the claim that being free of an occasional mild headache is a sufficiently important benefit for an individual's life that the importance of making it available justifies imposing on another the burden of being involuntarily subjected to painful and debilitating medical experimentation. ${ }^{7}$ It is hard to see how a plausible argument for that claim might go.

\section{AGAINST THE FAVOURABLE RISK/BENEFIT RATIO REQUIREMENT}

Contractualist reasoning yields an intuitively plausible conclusion in the medical experimentation case just sketched. But it appears to support very counter-intuitive conclusions concerning the permissibility of conduct that imposes a risk of harm on others. Consider, for example, driving. Every time someone drives, there is a risk of others ending up harmed (even the most conscientiously driven cars sometimes go out of control). Over time, this risk is certain to eventuate in the lives of some as serious harm. To assess driving's permissibility on contractualist terms, it appears we need to ask whether the benefits an individual stands to gain if driving (subject to safety standards) is permitted are of sufficient importance to justify permitting the activity to one who has ended up seriously (perhaps fatally) harmed as a result of a driving mishap. It isn't obvious what might be said by way of an affirmative answer. But it is also difficult to accept that it is always impermissible to drive because, no matter how safely one does so, there is always a risk that doing so will result in some ending up seriously harmed. ${ }^{8}$

Part of the appeal of contractualism's understanding of permissible conduct as conduct that is justifiable to the point of view of anyone who stands to be affected by it is that it appears to block what utilitarian reasoning permits: the serious burdening of a few in order to secure lesser benefits for a great number of others. But that which accounts for this strength-only counting as relevant to a principle's assessment its implications for individuals - appears to undermine the account's plausibility when it comes to making sense of the permissibility of ordinary, socially productive, risk-imposing activities—such as any clinical trial that involves exposing participants to a serious risk of harm. The conclusion contractualist reasoning appears to in fact support regarding such trials (of which some early-phase HIV cure trials are an instance) is that what IRBs owe to those who would be willing to participate in them is to not allow it to proceed. They should not be allowed to proceed because doing so would not be justifiable to those who may end up seriously burdened as a result of their participation. This will often not be clear to those deliberating about whether or not to participate. They may, for instance, be self-deceived about the extent to which they stand to benefit from the outcome of the trial. Preventing the trial from going forward, then, can be seen to be akin to paternalistic intervention to protect those who might participate if the opportunity were to be made available.

The initial hypothesis was that contractualist reasoning would yield a plausible rationale for the favourable risk/benefit ratio requirement. It now appears that that hypothesis is mistaken. Some won't find this outcome surprising, being already convinced that it is only if we look to its implications for aggregate welfare will we find a consideration weighty enough to justify permitting an activity that imposes on some a risk of ending up seriously harmed or killed. ${ }^{9}$ The place to look for a plausible moral rationale for the favourable risk/benefit ratio requirement, therefore, is in utilitarian cost/benefit considerations. But 
utilitarian cost/benefit reasoning does not arguably support the favourable risk/benefit ratio requirement. Rather, it only requires that the aggregate benefits for individuals (though perhaps not the trial participants) be of sufficient importance to justify the potential burden trial participants may end up having to bear. ${ }^{10}$

On either contractualist or utilitarian terms, then, the requirement of a favourable risk/benefit ratio ends up looking morally unmotivated. Contractualism appears to lead us to conclude that it is always wrong to do what imposes a risk of harm on another, even if the risk/benefit ratio is favourable, while utilitarian thinking finds no objection in asking a few to bear the risk of ending up seriously burdened if doing so is necessary for potentially securing a great benefit for a large number of others.

The idea, however, that to permit clinical trials that do not have a decent chance of yielding results that will benefit the trial participants is to permit participants to be used in a morally objectionable way remains intuitively quite powerful. For this reason, it is worth looking more closely at the argument for why contractualist thinking will not yield a plausible moral rationale for requiring a favourable risk/benefit ratio.

\section{REASONABLY DISCOUNTING HARM}

The argument for why we can't look to contractualist thinking for a plausible rationale for the favourable risk/benefit ratio requirement is that contractualist reasoning leads us to conclude that it is almost always impermissible to do what exposes another to a risk of ending up in a harmed state. In this section, I will discuss why I think contractualist reasoning supports no such conclusion. That will clear the way for a defence of the favourable risk/benefit requirement on contractualist grounds. But in the next section, I will offer some reasons for doubting that such a defence is readily available after all.

Where the argument for why contractualist thinking condemns as impermissible most activities that involve exposing another to a risk of harm goes wrong, I believe, is in overlooking the role principles play in the account. Principles no one can reasonably reject figure in the account as forming a system of principles, roughly analogous to the principles constitutive of a legal system. The system establishes (very roughly) how it is and is not permissible for a person to relate to others in a certain type of situation. To take a certain course of conduct to be permitted, here and now, by a principle no one can reasonably reject, is to hold there to be good reasons that support the permissibility of any person similarly situated conducting himself in that way, and that the reasons supporting this standing permission are sufficient to defeat objections to there being a standing permission to relate to another in this way.

The relevant reasons concern the implications of the proposed permission as assessed from the different points of view of those who stand to be affected. But because what is licensed by a principle is the general permissibility, in a certain type of situation, of one person relating to another, or others, in a certain way, and there is no way of knowing how often it will obtain or who will find themselves in it, the points of view in question are not those of actual, particular individuals, but are, rather, representative individual standpoints.

A 'standpoint', as the term is being used here, is an abstraction, a way of referring to the reasons that persons in certain circumstances (assumed to have certain 'normal' capacities for discernment, self-control, planning, etc) typically have for caring about or wanting certain things ('generic reasons'), such as a degree of personal privacy, security against bodily injury, the freedom to nurture personal relationships with friends and intimates, and sole discretion concerning how one's body is used. The relevant standpoints for assessing principles governing promissory obligations, for example, are those of the promisor and the promisee, each of which is associated with certain characteristic interests-such as the promisee's interest in being assured that certain things will or will not be done (unless he says otherwise), and the promisor's interest in being able to assure the promisee, if he seeks assurance. In the context of a clinical trial, the relevant standpoints would be, for instance, those of individuals who stand to benefit from the results of the trials, of the investigators pursuing a deeper scientific understanding of a disease and its treatment, and of those who put themselves as risk as participants.

For reasons I won't go into here, evaluating the permissibility of a standing permission to pursue an activity that will result in some being exposed to a serious risk of harm in light of its implications for relevant individual standpoints introduces a non-aggregative, ex ante point of view from which the permissibility of doing what puts others at risk is to be evaluated. Looked at in this way, the relevant questions in evaluating the permissibility of doing what puts some at risk are, first, what are the reasons, associated with the relevant standpoints, that it might matter to an individual's life that it be permissible to pursue this type of conduct? How compelling are these reasons? Second, to how great a risk will the standpoint of those put at risk be exposed? To what extent can this risk be reduced by requirements of due care ${ }^{11}$

The argument for why contractualism identifies most risk-imposing activities as impermissible relies on the inference that, first, because permitting a risk-imposing activity will, over time, result in someone ending up seriously harmed and second, because permitting that activity does not benefit any individual to a great enough extent to justify to one who has ended up harmed his having to take on that burden, contractualist reasoning should lead us to conclude that the pursuit of the risk-imposing activity in question is impermissible. What I have just argued is that this inference is illegitimate. A person may end harmed as a result of another engaging in a risk-imposing activity. But whether or not its pursuit was impermissible, and thus wrongs him, turns on the implications of permitting the activity for anyone in his circumstances. Because the activity is a risk-imposing activity, every instance of it being pursued was not certain to result in anyone in his circumstances ending up harmed; he was unlucky that the risk eventuated in his life. Whether or not he has actually been wronged turns on a comparison of that harm discounted by the probability of it eventuating in anyone's life with the benefit for an individual of permitting the activity in question.

Because this is a non-aggregative approach to assessing the permissibility of risk-imposing conduct, how many stand to benefit and how many will be put at risk are not relevant considerations. The worry that, in permitting a risk-imposing activity, a few are being sacrificed in order to benefit a great many others, cannot, therefore, be motivated on its terms. More importantly, the permissibility of risky conduct may be justifiable to the standpoint of those at risk even if permitting it cannot (even indirectly) be expected to benefit anyone aptly described by it. That there is a legitimate interest in having access to a benefit associated with certain standpoints, one that will be secured by permitting, in some form, a risky activity, is a good reason, from the standpoint of those who will be at risk, to accommodate that interest by taking on the burden of being put at risk. 


\section{REASONABLY REJECTING THE FAVOURABLE RISK/BENEFIT RATIO REQUIREMENT}

Let me now turn to how these points bear on the permissibility of early-phase HIV cure trials. Whether or not a trial is permissible turns on the value for an individual of its results and the risk of harm to which those who choose to participate will be exposed. But because nothing in the contractualist account requires that those exposed to a risk of harm as a result of an activity being permitted be potential beneficiaries of doing so, the comparison is an interpersonal comparison, not an intrapersonal comparison. The assumption that justifying to a person imposing a risk of harm on him requires that there be, at least potentially, some benefit for him in doing so is, I suspect, a large part of why it seemed intuitive that contractualist reasoning would yield moral support for the favourable risk/benefit ratio requirement.

Safety standards, accreditation and qualification requirements, monitoring, etc, all help reduce the risk associated with a trial, which in turn makes permitting it to proceed easier to morally justify to all those who might be affected by it. It is also important that potential participants in a trial be fully informed, and that their participation be voluntary. The risk might be very low, and the benefit of great significance, but that doesn't change the fact that trials involve intentionally doing things to a person's body and each person has very good reasons for wanting sole discretion over decisions concerning what is to be done to his body by another.

The case of early-phase HIV cure trials is murkier because both the risks participants face and the potential benefits for individuals of the therapy being tested are, given the available evidence, relatively unknown (working out what they are is part of the point of a phase II trial). What requires justification, then, is making opportunities available to individuals to participate in an activity that exposes them, not to a risk of harm, but to a situation of uncertainty as to how likely it is a person will end up in a harmed state.

Tentatively, I take this to point to the idea that in thinking about the justifiability to all relevant standpoints of early-phase HIV cure clinical trials, what we should focus on are both the reasons individuals have for wanting an HIV cure as compared to antiviral therapy, and the non-instrumental reasons why it might be important to a person to have the opportunity available to him to participate in an early-phase HIV cure trial. One such reason could be the expressive value of participating in the battle to eradicate the disease associated with a degree of social stigma.

Emphasising the importance of this kind of consideration is compatible with the importance normally attached to ensuring that participants in trials fully understand the risks for them involved in, and the potential value of, the research. The importance of doing so, however, might be better understood, not as a matter of ensuring that those considering participating in a trial are in a position to make a fully informed gamble, but as organising the circumstances in which a person is deliberating about whether to participate in a trial in such a way as to make it more likely that what will move him to participate, if he should choose to do so, are considerations like the expressive importance to him of participating rather than a concern with his personal welfare. The former is a good reason to participate that is largely independent of the risk of ending up in a harmed state, while the later, given the paucity of evidence with which to assess the matter, is not.

\section{CONCLUSION}

In this paper, I've argued that contractualist reasoning does not support the requirement that the risk/benefit ratio for participants in a clinical trial must be favourable if proceeding with the trial is to be morally defensible. I take this conclusion to be both important and surprising. It is well known that consequentialist or utilitarian moral reasoning does not appear to provide a moral basis for the favourable risk/benefit ratio requirement. But that is what one would expect-consequentialists often argue that the interests of individuals sometimes need to be subordinated to the interests of the broader society. Contractualist reasoning stands opposed to that kind of thinking, so it is reasonable to expect that contractualist reasoning could be deployed in defence of the favourable risk/benefit ratio requirement. In concluding that it does not, I have tried to identify some reasons for thinking whether or not a proposed clinical trial is potentially exploitative of the participants is independent of the question of whether or not the risk/benefit ratio for participants is favourable.

Funding National Institute of Allergy and Infectious Diseases (grant no. 1 R01 Al114617-01A1; 1 R56 Al114617-01).

Competing interests None declared.

Provenance and peer review Commissioned; externally peer reviewed.

Open Access This is an Open Access article distributed in accordance with the Creative Commons Attribution Non Commercial (CC BY-NC 4.0) license, which permits others to distribute, remix, adapt, build upon this work non-commercially, and license their derivative works on different terms, provided the original work is properly cited and the use is non-commercial. See: http://creativecommons.org/ licenses/by-nc/4.0/

\section{REFERENCES}

1 Eyal N, Kuritzkes DR. Challenges in clinical trial design for HIV-1 cure research. Lancet 2013;382:1464-5.

2 Evans D. What would you do to cure HIV? http://www.aidsmeds.com/articles/hiv cure ethics 2042 20510.shtml (accessed 11 Dec 2015).

3 London A. Clinical equipoise: foundational requirement or fundamental error? In: Steinbock B, ed. Oxford handbook of bioethics. New York, NY: Oxford University Press, 2007:571-96.

4 Parfit D. On what matters. Vol 1. Oxford, UK: Oxford University Press, 2011.

5 Scanlon T. What we owe to each other. Cambridge, MA: Harvard University Press, 1998.

6 Kumar R. Contractualism. In: LaFollette H, ed. International encyclopedia of ethics Malden, MA: Wiley, 2013.

7 Parfit D. Justifiability to each person. Ratio 2003;16:368-91.

8 Ashford E. The demandingness of Scanlon's contractualism. Ethics 2003;113:273-302.

9 Fried B. Can contractualism save us from aggregation? J Ethics 2012;16:39-66.

10 Brock D, Wikler D. Ethical issues in resource allocation and new product development. In: Dean J, Breman J, Measham A, et al, eds. Disease control priorities in developing countries. 2nd edn. Oxford, UK: Oxford University Press, 2006:259-70.

11 Kumar R. Risking and wronging. Philos Public Aff 2015;43:27-51. 